\title{
Research Paper: Professional Ethics in Physiotherapy: ๑) Existing Challenges and Flaws
}

\author{
Amirahmad Shojaei ${ }^{1}$ (D, Masoud Ghofrani ${ }^{2 *}$ (D) \\ 1. Department of Medical Ethics, School of Medicine, Tehran University of Medical Sciences, Tehran, Iran. \\ 2. Department of Physiotherapy, School of Rehabilitation, Tehran University of Medical Sciences, Tehran, Iran.
}

\begin{tabular}{|l|l|}
$\begin{array}{l}\text { Use your device to scan } \\
\text { and read the article online }\end{array}$ & $\begin{array}{l}\text { Cittation: Shojaei A, Ghofrani M. Professional Ethics in Physiotherapy: Existing Challenges and Flaws. Journal of Modern } \\
\text { Rehabilitation. 2018; 12(1):39-44. http://dx.doi.org/10.32598/jmr.12.1.39 }\end{array}$ \\
doi: $:$ http://dx.doi.org/10.32598/jmr.12.1.39
\end{tabular}

Funding: See Page 43

(c) Copyright: The Author(s)

Article info:

Received: 03 Jul 2017

Accepted: 26 Nov 2017

Available Online: 01 Jan 2018

\section{Keywords:}

Professional ethic, physical therapy, Challenges and flaws

\begin{abstract}
A B STRACT
Introduction: Physiotherapy requires close and prolonged contact of physical therapist with patient during several sessions. For this reason, many associations in other countries have formulated code of ethics for physiotherapy which referred to the most important responsibilities in this field. Despite formulation of ethical codes in many countries, these codes have not yet been outlined in Iran. Therefore, this research has been conducted to identify the physiotherapy ethical imperfections and challenges and in Iran.
\end{abstract}

Materials and Methods: This study was a qualitative research in which methods of interview with authorities and focused group discussions were used. Participants in this study were 15 persons, who were purposefully selected from four professional groups including physicians, physical therapists, specialists on medical ethics and directors of physiotherapy centers.

Results: After data saturation, texts of interviews were typed verbatim. These texts were repeatedly studied by the interviewer and their results were 187 raw and rudimentary sentences. Extracted data were analyzed, reviewed and revised by the authorities on the subject and eventually the data were arranged in 4 domains of patient, physician, physical therapist, and treatment center.

Conclusion: Findings of this research indicate the ethical challenges present in our country in the field of physiotherapy in four domains. To promote professional ethics in physiotherapy, all four parties should be aware of their rights and duties and follow ethical principles and regulations.

\section{Introduction

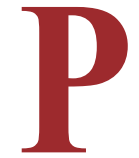 \\ hysical therapy refers to services provided by physical therapists to clients to devel- op, maintain, and restore their maximum movement and functional ability through-}

out their lifespan. This service is offered where normal movement and function are threatened by ageing, injury, pain, diseases, disorders, conditions, or environmental factors and with the understanding that functional movement is central to what it means to be healthy [1]. Physical therapists are involved in identifying and maxi-

\footnotetext{
* Corresponding Author:

Masoud Ghofrani, PhD

Address: Department of Physiotherapy, School of Rehabilitation, Tehran University of Medical Sciences, Tehran, Iran.

Tel: +98 (21) 22007719

E-mail:masood.ghofrani@yahoo.com
} 
mizing patients' quality of life and movement potential within the context of promotion, prevention, treatment/ intervention, habilitation, and rehabilitation.

These contexts encompass physical, psychological, emotional, and social wellbeing. Physical therapy requires close and prolonged contact of physical therapist with patient during several therapy sessions. Besides Tom Beauchamp and James Childress four principles of ethics included in this therapeutic area [2], more ethical principles should be discussed that contains professional ethics in the field of physiotherapy because physical therapists have close and prolonged and repeated contacts with their patients $[3,4]$.

For this reason, many associations in other countries have issued code of ethics for physiotherapy which referred to the most important responsibilities and dos and don'ts in this field. For example, the American Physical Therapy Association considers that physical therapists are duty bound to respect all people's rights and inherent dignity; to be trustworthy and compassionate in observing the rights and needs of patients and referrers; to be responsive for professional judgment; to demonstrate their truthfulness in their contacts with the patient, their family, colleagues, students, participants in research studies, other specialists, employers and the society; to carry out their legal and professional obligations; to advance their specialist capabilities by constant acquisition of knowledge, skills, capabilities and professional behaviors; and to advance organizational behavior and work method in favor of the patient.

They should endeavor at national and global level for the needs of people's health [5]. Also, the Canadian Physiotherapy Association considers that physical therapists should esteem the patients who refer to them, to respect their rights for decision making, to be useful for the patient, to be careful so not in any way harm the patient, to be honest and truthful with them, and to be trustworthy [6].

Despite formulation of ethical codes in other countries, physical therapists are confounded by ethical codes in dealing with different conditions where patients no longer are able to move, overweight, have contagious infections, or lack suitable financial condition and so on the. With a glance at official sources and sites of our country's rehabilitation schools, no station has been arranged for ethics, including professional ethics and physiotherapy ethics and no contents have been published so far. Also considering different social and cultural conditions in different societies, the need for formulating professional ethics in physiotherapy is felt even more. Therefore, this research was conducted with the objective of describing and analyzing the gaps and challenges of ethics in physiotherapy in our country.

\section{Materials and Methods}

This study is a qualitative research in which methods of interview with authorities and focused group discussion were used with the aim of identifying ethical gaps and challenges in physiotherapy in our country and in the four fields of physical therapist, patient, physician, and physiotherapy centers. The content analysis was carried out on the resulting data which were description of the present situation. In qualitative studies, the sample size depends on the data saturation. In this study, the researcher reached data saturation after 15 interviews. It means that the researcher did not receive any new information while continuing the interviews and no new code was added to the previous data.

Participants in this study were purposefully selected from four groups, including physicians who referred many patients to physiotherapy centers because of their specialty field (three specialists in physical medicine and rehabilitation, an orthopedics specialist, a neurologist, a neurosurgeon, and a general practitioner), physical therapists who had at least 6 years of practice in the field of physiotherapy (two physiotherapy experts) and also university professors with more than 20 years of background in teaching and conducting execution affairs and activity in physiotherapy treatment (two university assistant professors), specialists on medical ethics (two university assistant professors) and directors of physiotherapy centers (two directors of public and private rehabilitation centers), and the number of participants was finalized after data saturation.

Method of inquiry in the interviews was using openended questions [7]. The interviewer at first discussed general points, without stating examples of medical and professional ethics, and also discussed multiple responsibilities of physical therapists regarding patients and physicians and colleagues. Then, the interviewee was asked for his or her opinion regarding the standards, challenges, objectives, and ethical examples under present conditions. The interviewer did not set forth any limits and did not impose any particular line of thought on the interviewees.

Based on their experiences and their mental preferences the interviewees discussed ethical subjects, and examples and challenges in the field of physiotherapy. 
The duration of interviews had no limits and it would continue to concurrence by the interviewee. Permission was obtained from the interviewees for recording and they were assured that after the contents are written down then the audio files will be deleted.

\section{Results}

In conventional content analysis method, after extracting the meaning units, the researcher reads the text several times to extract the codes. During the summarizing process, the codes are classified and placed in relevant categories according to their content similarities. In this study, after saturation of data and completion of data collection phase, texts of interviews were typed verbatim. These texts were studied several times by the interviewer and their results were 187 raw and rudimentary sentences.

These sentences were compared continuously and concurrently and after leaving out and merging redundant and similar sentences, 60 propositions were remained that each one was considered a meaning unit and indicator of the participants' viewpoint and outlook. Then, these 60 meaning units became source of content analysis and out of categorized meaning units, the relevant codes were extracted. Related codes were analyzed with each other.

In this analysis, the opinions of authorities on the subject were utilized and messages of each group of sentences or codes were extracted. Extracted messages were analyzed, reviewed and revised by the authorities on the subject and eventually the data were arranged in 4 groups: challenges related to the patients, challenges related to the physicians, challenges related to the physical therapists, and challenges related to the treatment centers. In the next stage, results derived from content analysis became subject of exchange of views through forming two group sessions for deep discussion. In total, two sessions of focused group discussion were held and in each session, seven participants were present [8].

At the outset of each session, the director of the program described the method of analysis and the way the data were accessed. Next the discussion was conducted and the conclusion was arrived. The sessions was directed by one of the authorities on physiotherapy and facilitator of the ses-

Open-ended questions interviews from 15 selected specialist

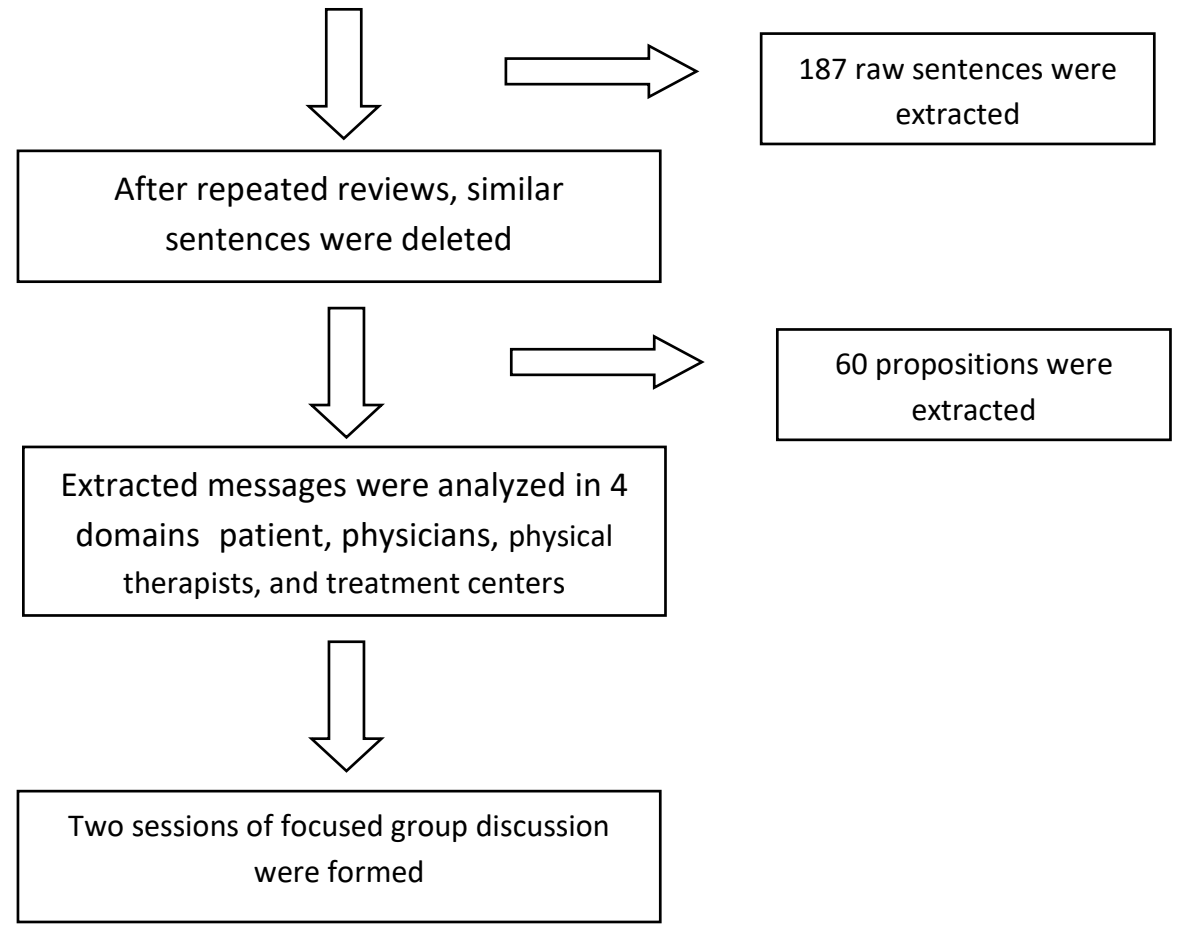

Figure 1. The procedure of qualitative research 
sions was the project director. Each session was managed and facilitated in a way that at the end the opinions of those present at the session could be summed up. Figure 1 shows the steps in conducting the research.

\section{Discussion}

Findings of this research indicate the ethical challenges present in our country in the field of physiotherapy in the four domains of physicians, patients, treatment centers, and physical therapists that are obtained after analysis of interviews and focused group discussions.

\section{Challenges related to the physician}

Physicians' knowledge of the science of physiotherapy is generally less than sufficient. They may refer the patient to the physiotherapy centers without writing down the diagnosis. They would specify the type of modality and offer professional comment and would not allow the therapist to exercise his or her opinion. Many physicians do not engage in exchange of opinion with physical therapists and it seems as though there is a major gap between physicians and therapists. At times a physical therapist does not agree with the physician's diagnosis or the treatment proposed by the physician. Sometimes, the physical therapist act on his or her own opinion and at other times follows the physician's order. However, there is always an ambiguity that who was right and whose opinion was sound and correct. If for any reason the patient would not recover, each one would blame the other party. Some physicians refer the patients to particular physiotherapy centers and split the fees with them, and at times the physiotherapy administration is performed in excess of what is needed [9-12].

Many therapists out of fear of less referral to them do not challenge the physician's prescription. Some physicians would even supply limited physiotherapy services at their own medical office and therefore, this would lead to excess prescription. Since medical schools generally do not offer any curriculum or course units for physicians regarding physiotherapy; therefore, physicians usually lack sufficient knowledge and information regarding physiotherapy and do not write reasoned prescriptions. On the other hand, according to the regulations of the Ministry of Health, Treatment and Medical Education, physical therapists are not allowed to act upon treatment of the patient without instructions by the physician, but contrary to the laws in developed countries [13], in Iran direct access does not have legal acceptance. However, physical therapists are required by professional principles to examine the patient at each session and then employ their knowledge and skill for choosing the best treatment method.

Considering these points, the physicians are generally hesitant to take note of the physician's instructions and this in itself creates a great challenge between the physician and the physical therapist. A challenge which often harms the patient.

\section{Challenges related to the patient}

Some patients based on their beliefs refrain from treatment by physical therapists of opposite sex. On the contrary, some patients due to some concerns express reluctance toward treatment by physical therapists of the same gender and insist on treatment by physical therapist of opposite gender, and this issue is seen more in male patients. Some male patients after a few treatment sessions by a female therapist express interest and request for a relationship with her that often causes inconvenience, anxiety and tension for the female physical therapist. Some patients with poor hygiene and cleanliness annoy their physical therapists that causes decline in the quality of treatment by the physical therapist.

Some patients due to many reasons including financial problems request for limited and inexpensive physiotherapy treatment that would lead to confusion for the physical therapist. Some patients in the beginning of physiotherapy are not informed on the process of treatment and therefore become hesitant to continue treatment, and consequently the effectiveness of treatment reduces. Before starting treatment the physical therapist should inform the patient to attract his or her cooperation in the treatment. Sometimes the physical therapist does not use completely his or her scientific and actual skills (manual techniques, exercise therapy, lifestyle training, and so on) in treating their patients and suffice themselves only with using electrotherapy equipments or other devices.

This results in decline of treatment efficacy. Many patients are not aware of their rights in the treatment by physiotherapy, including that they should be fully respected, their privacy should be observed, their medical and non-medical secrets should remain confidential, should have the option of selecting their physical therapist, should recognize their type of physiotherapy treatment and accept it knowingly and ensure that the concurrence have been reached between the diagnosis of their physician and the opinion of their physical therapist. Therefore, a charter for the rights of patient in the 
field of physiotherapy would be of great help in resolving existing challenges.

\section{Challenges related to treatment centers}

Some physiotherapy centers use equipments with poor quality. Also, due to limitation in the physical space, they use rooms or multi-bed cabins that challenges patients' privacy. By paying low fees the physical therapist loses motivation and subsequently the quality of services by the physical therapist declines. Because of rotation of therapists' work shift, the patients cannot choose the therapist. As part of the fees paid by insurance companies is low, some physiotherapy centers underprovide their physiotherapy services for patients covered by insurance. Physiotherapy centers lack a charter for observing the patient's rights which of course arises from failure by related organizations.

\section{Challenges related to physical therapists}

Some physical therapists do not have sufficient knowledge and skills or because of lack of familiarity with professional ethics in physiotherapy they only use electrotherapy equipments and limit physiotherapy to electrotherapy. Some physical therapists fully examine the patient and based on the results of their examinations and also the physician's instructions, they choose the best treatment method. On the contrary, some others only act based on the physician's opinion and would not conduct clinical examinations in their therapeutic sessions. Some physical therapists accept direct referrals; however, some others only accept patients in case the physician instructions exist.

Some physicians provide the patient with required information and act upon treatment based on the patient's conscious consent while others do not act accordingly and without the patient's awareness or obtaining the patient's consent they use different therapeutic modalities. Some physical therapists do not treat patients of their own gender while others do not consider said limitation as an impediment for their work. Some physical therapists would never seek a relationship with the patient that is not related to therapeutic procedure and think only of treatment of their patients, while some others establish communication with their patients that is not related to the treatment.

Physiotherapy is a group conducted procedure by the physician and physical therapist and patient at specific treatment centers. Therefore, for advancing professional ethics in physiotherapy, all four parties who provide ser- vices (physician, patient, physical therapist, and physiotherapy service enters) should be aware of their rights and duties and have ethical principles and regulations to follow. Since, the Ministry of Health, Treatment and Medical Education has not taken coherent steps for education of professional ethics in physiotherapy, the following articles should be implemented:

Physical therapists should be placed under professional ethics education and physiotherapy ethics and become aware of patients' rights. A charter should be codified for the patients' and the therapists' rights in the field of physiotherapy and published to the public. Ethical codes in physiotherapy should be formulated and placed at the disposal of physical therapists and the public. Physicians should be required to provide conditions for contacting the physical therapist for consultation and exchange of opinion when writing physiotherapy prescription for patients.Treatment centers providing physiotherapy services should be required and tasked with providing standard services regarding quantity and quality in this field and should be constantly supervised on the quality of their services.

\section{Ethical Considerations}

\section{Compliance with ethical guidelines}

Ethical issues including plagiarism, informed consent, misconduct, data fabrication and/or falsification, double publication and/or submission, redundancy, etc. have been completely observed by authors.

\section{Funding}

This research is completely independent and has not received any funding from any organization or institution.

\section{Conflict of interest}

The authors declared no conflict of interest.

\section{Acknowledgments}

We appreciat the officials and professors of the Hamadan University of Medical Sciences, as well as the senior managers and nurses who helped us with this research.

\section{References}

[1] World Confederation for Physical Therapy. Policy statement: Regulation of the physical therapy profession [Inter- 
net]. 2017 [Updated 2017 April 25]. Available from: www. wcpt.org/policy/ps-regulation

[2] Beauchamp TL, Childress JF. Principles of biomedical ethics. New York: Oxford University Press; 2013.

[3] World Confederation for Physical Therapy. Ethical Principles [Internet]. 2017 [Updated 2017 April 13]. Available from: www.wcpt.org/ethical -principles

[4] World Confederation for Physical Therapy. Policy statement: Ethical responsibilities of physical therapists and WCPT members [Internet]. 2017 [Updated 2017 April 18]. Available from: www.wcpt.org/policy/ps-ethical-responsibilities

[5] American Physical Therapy Association. Code of Ethics for the Physical Therapist. Virginia: American Physical Therapy Association; 2010.

[6] http:/ / www.scpt.org/document/3556/Harmonized_ Code_of_Ethical_Conduct.pdf [Updated 2016 July 15]

[7] Singer E, Couper MP. Some Methodological Uses of Responses to Open Questions and Other Verbatim Comments in Quantitative Surveys. Methods, Data, Analyses. 2017; 11(2):115-134. [DOI: 10.12758/mda.2017.01]

[8] Escalada M, Heong KL. Focus group discussion [Internet]. 2014 [Updated 2014 May 23]. Available from: https://www. researchgate.net/publication/242589494_Focus_Group_Discussion_1

[9] Parsa M, Larijani B, Aramesh K, Nedjat S, Fotouhi A, Yekaninejad MS, et al. Fee splitting among general practitioners: A cross-sectional study in Iran. Archives of Iranian Medicine. 2016; 19(12):861-5. [PMID]

[10] American Psychiatric Association. Know the law on fee splitting [Internet]. 2006 [Updated 2006 November 2006]. Available from: http://psychnews.psychiatryonline.org/ doi/10.1176/pn.41.21.0019c

[11] Miller C. Health law: Splitting fees or splitting hairs? Virtual Mentor. 2009; 11(5): 387-89 [DOI:10.1001/virtualmentor. 2009.11.5.hlaw1-0905] [PMID]

[12] Choudhry S, Choudhry NK, Brown AD. Unregulated private markets for health care in Canada? Rules of professional misconduct, physician kickbacks and physician self-referral. Canadian Medical Association Journal. 2004; 170(7):1115-8 [DOI:10.1503/cmaj.1031363] [PMID] [PMCID]

[13] World Confederation for Physical Therapy. Policy statement: Direct access and patient/client sel-referral to physical therapy. [Internet]. 2017 [Updated 2017 April 10]. Available from: www.wcpt.org/policy/ps-direct-access 